12. Brahm E. Conflict Stages // Burgess G., Burgess H. (eds). Beyond Intractability. Boulder, 2003.

13. Lerma M. Ethnic Conflict and Relationships to Territory // Paper presented at the annual meeting of the American Political Science Association. Marriott, Loews Philadelphia, and the Pennsylvania Convention Center, Philadelphia, PA, Aug 31, 2006.

14. Gurr R.T. Peoples Against States: Ethnopolitical Conflict and the Changing World System // International Studies Quarterly. 1994. Vol. 38/3. P. 347-377.

\title{
ФРАКТАЛЬНОСТЬ И ИХ ИНТЕРПРЕТАЦИЯ В ПСИХОЛОГИИ Жукова Д.И.
}

Психофизиология и экспериментальная психология с момента своего формирования как научных дисциплин постоянно ставили перед собой цель поиска и разработки наиболее конструктивных способов воздействия на психические функции, процессы и состояния личности [11]. Актуальные вопросы в настоящий период времени, на наш взгляд, касаются повышения работоспособности, снижение утомляемости, повышение психического тонуса человека, способствование запуска интегративных и восстановительных процессов. Сегодня существуют различные технологии корректирующего влияния на функциональное состояние личности, многие из которых имеют широкое распространение и пользуется популярностью, среди них различные психотехнологии, формы воздействия, основанные на методах суггестивной психотерапии, сенсорно-полевые коррекции, мануальная терапия и т.д [1]. Современный этап развития психофизиологии и экспериментальной психологии протекает в условиях быстрого научно-технического прогресса, отражающего доступность многих уникальных технологий. Поэтому, на наш взгляд, наиболее интересной представляется работа, связанная с определенными способами воздействия на функциональное состояние личности, повышение его психофизиологического статуса, исключающая использование инвазивного метода и не требующая специфического вмешательства специалистов. Особый интерес вызывают методы воздействия на психофизиологический статус индивида через зрительный анализатор, в частности, метод воздействия на состояние сознания с помощью хаотических изображений - фракталов [2]. Фрактал - это самоподобие или, другими словами, объект, совпадающий с частью самого себя приближённо или в точности, то есть целое имеет ту же форму, что и одна или более частей [8]. Впервые самоподобные множества с необычным свойством появились в XIX веке в результате изучения непрерывных недифференцируемых функций (например, множество Кантора, функции Больцано и Вейерштрасса). В 1975 г. термин «фрактал» был введён Бенуа Мандельбротом, получивший впоследствии широкую известность с выходом его книги «Фрактальная геометрия природы» в 1977 году [9, 10]. Данный метод представляет особый интерес не только потому, что фрактальные узоры необыкновенно красивы, неодолимо влекут за собой, оказывая сильное влияние на сознание индивида, 
но еще и потому, что многие процессы, протекающие в живых системах, имеют фрактальную природу. Например, электрическая активность мозга, сердца и любых других электрически активных клеток организма имеет хаотические составляющие и свою специфическую фрактальную размерность. Этот метод часто используется во многих областях - от компьютерной до искусства, но научного обоснования не имеет. Опыт применения подобного метода позволил предположить, что основным влиянием его является изменение состояния сознания [3]. Данные специфические изменения не сводятся к простейшим изменениям памяти, внимания и других специфических процессов, поэтому в нашем исследовании психофизизиологических коррелятов мы используем еще нелинейные методы анализа ЭЭГ и психодиагностические методики для отслеживания психологических особенностей изменения сознания.

В математике и кибернетике фракталы отражают множественную дробную размерность, имеющую большое количество точек в евклидовом пространстве (в смысле Минковского или Хаусдорфа), либо метрическую размерность, отличную от топологической, поэтому их следует отличать от других геометрических фигур, ограниченных конечным числом звеньев.

Данное множество является нечто промежуточным между точками и линиями, линиями и поверхностями, поверхностями и телами, они похожи пористые губки, ветвящиеся подобно лишайникам структуры, пылевидные канторовы множества. Необычным свойством всех «фрактальных» форм является их характерный многократно повторяющийся паттерн на нисходящих уровнях, приводящий их части на любом уровне в форму, напоминающей целое [4]. Мандельборт иллюстрировал это свойство самоподобия, отламывая кочан цветной капусты и продолжая демонстрацию, делая часть дальше, изымая еще один кусок, который тоже похож на очень маленький кочан. В итоге, каждая часть выглядит как целая. Форма целого подобна самой себе на всех уровнях выбранного диапазона.

В природе существует множество различных примеров самоподобия, например, камни в горах схожи на маленькие горы, края облаков или ответвления молнии снова и снова напоминают один и тот же паттерн, побережье моря можно разделить на все более мелкие части, и каждая из них будет повторять подобные друг другу очертания береговой линии. Кроны дерева, фотографии дельта реки или ветвления кровеносных сосудов имеют проявления паттернов такого разительного сходства, что порой крайне сложно отличить один от другого. Подобие образа совершенно различного масштаба было известно очень давно, но до Мандельброта никто не владел математическим языком для описания этого феномена. Поэтому в середине 70х гг. Мандельброт, опубликовав свою новаторскую книгу, еще сам не предполагал о связи фрактальной геометрии с теорией хаоса, но ему и его коллегам - математикам не пришлось много времени терять, чтобы обнаружить странные аттракторы, послужившие в дальнейшем изысканнейшими примерами фракталов. Увеличивая части их структуры, можно обнаружить многослойную субструктуру, в которой снова и снова повторяются одни и те же паттерны [5]. В связи с этим странные аттракторы стали определяться как 
траектории в фазовом пространстве, проявляя в себе черты фрактальной геометрии. Еще одна важная связь между фрактальной геометрией и теорией хаоса отразилась в переходе от количества к качеству. Мандельброт подчеркнул эту важную особенность фрактальных форм, задавая провоцирующий вопрос о протяженности побережья Британии. Он указал на то, что, на этот вопрос нет однозначного ответа, поскольку измеряемую длину можно растягивать до бесконечности, переходя каждый раз к все более мелкому масштабу. Но возможно определить число в диапазоне от 1 до 2, характеризуя изрезанность побережья. Для британского побережья это число равно около 1,58 , для более изрезанного норвежского берега оно приближено к 1,7027. Если число имеет определенные свойства размерности, его обозначают как фрактальную размерность. Извилистая линия имеет больше пространства на плоскости, чем одномерная гладкая линия, но меньше, чем сама двухмерная плоскость. Чем больше изрезана линия, тем ее фрактальная размерность ближе к числу 2. Например, скомканный лист бумаги занимает больше пространства, чем плоскость, но меньше, чем сфера. Следовательно, чем плотность скомканной бумаги выше, тем ее фрактальная размерность будет ближе к числу 3. Абстрактная математическая идея концепции фрактальной размерности превратилась со временем в мощный инструмент анализа сложных фрактальных форм из-за отличного соответствия жизненного опыта людей. Чем более изрезаны очертания границ облаков или молний, чем менее сглажены формы гор или побережий, тем выше их фрактальные размерности [6]. Для моделирования фрактальных форм, встречающиеся в природе, можно построить геометрические фигуры, отражающие точное самоподобие. Важным методом для построения таких математических фракталов послужила итерация, в виде многократного повторения определенной геометрической операции. Процесс итерации, способствующий к преобразованию пекаря - это математическая операция, лежащая в основе странных аттракторов, по сути, стал главной математической особенностью, объединившей теорию хаоса с фрактальной геометрией. Благодаря компьютерам простые геометрические итерации можно применять множество раз в разных масштабах, формируя так называемые фрактальные подделки - компьютерные модели животных, деревьев, растений, гор, береговых линий и т.П., имеющих поразительное сходство с реальными формами, которые встречаются в жизни. Данный новый математический аппарат позволил ученым построить точные модели различных нерегулярных естественных форм [7]. Занимаясь данным моделированием, они совместно обнаружили наличие фракталов. Фрактальные паттерны облаков, которые изначально вдохновили Мандельброта на поиск иного математического языка, скорее всего, самые совершенные. Их самоподобие охватило семь порядков величин, из чего следует, что если границу облака повысить в 100000000 раз, она будет иметь все ту же привычную форму. Открытие Мандельбротом математической структуры, обладающей в высшей степени сложностью и способной воспроизводиться с помощью очень простой итеративной процедуры, явилось пиком фрактальной геометрии. Важнейшей областью применения фрактальной геометрии с 1980-х гг. была биология и 
медицина. В Будапеште в 1993 г. состоялась первая международная конференция «Фракталы в естественных науках». Проводились конференции, касаемые вопросов фрактального анализа, в частности, методы обработки фрактальных процессов в энцефалографии и кардиографии. Вышел в свет специализированный международный журнал «Фракталы», издательства Word Scientific.

\section{Литература}

1. Балин В.Д. Лабораторные и практические занятия к курсу психофизиологии. Учебно-методическое пособие. СПб., 2007

2. Балин В.Д. Психофизиология для психологов. Учебно-методическое пособие. С-Пб., 2008.

3. Вартанов А.В. О влиянии нарушения цветового зрения на формирование цветового семантического пространства // Психологический журнал. - 1996.-№ 2. - С . 166-170.

4. Данилова Н.Н., Фуколова Ю.В. Влияние функционального состояния на перцептивное и семантическое пространства у человека // Психологический журнал. - 1996. - № 3. - С 70- 81.

5. Измайлов Ч.А., Титова Н.А. Четырехмерное пространство восприятия эмоциональной экспрессии // Вестник Московского университета. Серия 14. Психология. 1999. - № 3. - 34.

6. Сандер Л.М. Фрактальный рост // В мире науки. - 1987. - № 3. - 62-69.

7. Свирский Я. Смысл события (на фрактальной кромке безумия) // Событие и смысл (Синергетический опыт языка). - М.: ИФ РАН, 1999. -С. 173202.

8. Симаков Ю. Рождение живых форм. В лабиринтах, теории формообразования//Знание - сила.- 1985.-№ 3 . - С . 20-21.

9. Синергетика и фракталы в материаловедении / В.С. Иванова и др. - М.: Наука, 1994.-383 с.

10. Смирнов Д. Мир образов и образ мира // Вестн. Моск. ун-та. Сер. Психология. - 1981. - № 2. - 15-29.

11. Кернберг, О. Тяжелые личностные расстройства. - М.: Класс, 2000, $464 \mathrm{c}$.

\section{ОСОБЕННОСТИ «КРИЗИСНОГО ПРОФИЛЯ» ЛИЧНОСТИ ПРЕПОДАВАТЕЛЕЙ ПРОФЕССИОНАЛЬНЫХ ОБРАЗОВАТЕЛЬНЫХ ОРГАНИЗАЦИЙ}

Журавлева Ю.А.

В научной литературе и психолого-педагогических исследованиях, посвященных проблеме психологического сопровождения образовательного процесса чаще всего рассматриваются вопросы, касающиеся воспитанников и обучающихся, сохранения их психологического здоровья, создания условий для всестороннего развития их личности, развития способностей, формировании компетенций и т.д. Говорится о субъектном подходе в образовании, о том, что дети являются активными участниками образовательного процесса, его 